ISSN: 0212-0267

DOI: http: //dx.doi.org/Io.I420I/hedu2019385976

\title{
INSTRUYENDO SOBRE LA RECREACIÓN: ALCOCER Y LA MODERACIÓN EN EL XVI, CLAVE EN LA EDUCACIÓN PARA EL JUEGO
}

\section{Instructing about recreation: Alcocer and the moderation of the XVI, key in education for the game}

Ignacio López de Prado Ortiz-Arce

Universidad de Salamanca

Correo-e: prarce@yahoo.es

Recepción: I2 de septiembre de 20I8. Envío a informantes: I9 de septiembre de 2018 Aceptación definitiva: I9 de noviembre de 2018

RESUMEN: En el año 1559 Francisco de Alcocer, fraile franciscano, escribe un tratado sobre el juego. La intención del fraile no es otra que instruir y poner orden en un asunto que tanto daño ocasionaba en la sociedad del XVI. Los juegos en general, pero especialmente los de azar, debido a su gran difusión y lo desmesurado de las apuestas, traerán consigo la existencia de diversas leyes, tanto canónicas como civiles. Todas estas leyes se prestarán a una gran confusión en cuanto a la interpretación de las mismas. Los razonamientos de los diferentes juristas sostienen posturas contrapuestas, desde que el juego es siempre lícito, a que no se podrá realizar sin pecado mortal. La moderación será la piedra angular que dictará la permisibilidad de la práctica lúdica.

Palabras Clave: Alcocer; tratado del juego; juegos prohibidos; apuestas; moderación.

ABSTRACT: In the year 1559 Francisco de Alcocer, Franciscan friar, wrote a treatise on the game. The intention of the friar is none other than to instruct and bring order in a matter that caused so much damage in the society of the xvI. Games in general, but especially those of chance, due to their great diffusion and the excessiveness of 
INSTRUYENDO SOBRE LA RECREACIÓN: ALCOCER Y LA MODERACIÓN EN EL XVI, CLAVE EN LA EDUCACIÓN PARA EL JUEGO IGNACIO LÓPEZ DE PRADO ORTIZ-ARCE

the bets, will bring with them the existence of various laws, both canonical and civil. All these laws will lend themselves to great confusion as to the interpretation of them. The reasoning of the different jurors hold opposing positions, since the game is always lawful, that cannot be performed without mortal sin. Moderation will be the cornerstone that will dictate the permissibility of playful practice.

KEY WORDS: Alcocer; treaty of the game; prohibited games; bets; moderation.

\section{Introducción}

J

UGAR HA SIDO INHERENTE AL SER HUMANO, igual que al resto de los mamíferos, desde el principio de los tiempos. Se ha seguido jugando por las mismas causas y razones en todas las etapas de la vida a lo largo de la historia, incluso muchas de las actividades lúdicas que se realizaron en el pasado nos siguen atrayendo y las seguimos utilizando. En Homo ludens, Johan Huizinga sostiene que el juego es inherente al ser humano, de la misma manera que el acto de pensar o el trabajo․ El aspecto lúdico está también íntimamente relacionado con el sociocultural, de tal modo que la cultura está dotada de un componente lúdico.

Las prácticas recreativas en el XVI se desarrollan en un escenario donde tiene preponderancia la escolástica, pero, al mismo tiempo, también pasa a ocupar un lugar relevante el humanismo europeo.

En España, los humanistas imperantes atribuirán a las actividades recreativas unos valores pedagógicos y formativos, necesarios en una nación que había descuidado el tratamiento corporal. Entre las figuras españolas destacadas del humanismo, son importantes las figuras de Antonio de Nebrija y Juan Luis Vives. Para Nebrija, una de las características fundamentales de la infancia es la actividad, esta debe ser aprovechada a través del juego "pues jugando incluso pueden aprender» ${ }^{2}$.

Juan Luis Vives estuvo en contra de la visión militarista que tenían los juegos y otras actividades físicas, los juegos debían servir para ayudar al crecimiento integral de la persona para fortalecer el cuerpo y como forma de emplear el tiempo libre. Así, el juego se tomará de la misma forma que la comida, la bebida o el sueño y las demás cosas que sirven para renovar, de otra manera será considerado vicio $^{3}$. A los jugadores les propone acerca de las apuestas que deben hacer, las cuales han de ser lo suficientemente moderadas, con el propósito de no arrepentirse por haber malgastado grandes sumas de dinero. Puesto que entonces el juego se convierte en tortura y sufrimiento, teniendo entonces justo la finalidad contraria de la que se pretende, es decir, distraerse y esparcirse de los trabajos diarios ${ }^{4}$.

Huizinga, J.: Homo ludens, Madrid, Alianza Editorial, 1938.

Esteban, I. y López, R.: Historia de la Educación en España y América: La educación en la España moderna. Madrid, Ediciones Morata, vol. 2, p. 92.

3 Vives, J. L.: Diálogos de Juan Luis Vives, traducción y correcciones por Cristoval Coret, 1759, p. 4I9.

${ }_{4}$ Ibidem, p. 42I. 
INSTRUYENDO SOBRE LA RECREACIÓN: ALCOCER Y LA MODERACIÓN EN EL XVI, CLAVE EN LA EDUCACIÓN PARA EL JUEGO

Por su parte, la Iglesia fomentará las celebraciones religiosas entrelazándolas con otras actividades recreativas en un intento de educar a sus fieles. Las representaciones de farsas u otro tipo de invenciones, por lo general, debían ser historias de la Sagrada Escritura. La intención es provocar la devoción en el pueblo, así como aprender el ejemplo que hemos de dar ante nuestro creador y las consecuencias que podría acarrear no llevar una vida ejemplar. Por eso, deben llevarse a cabo por personas que las representen con cierta compostura y conocimiento de la obra, «lo qual muchas vezes falta, y son tan grosseros los representadores y lo hazen con tan mal donayre, que son mas provocativos de risa que de deuocion: aunque por esto pues que su intencion es buena no se deuen condenar»s.

La fiesta será utilizada como válvula de escape para el vulgo. La necesidad de huir de la vida rutinaria para los más afortunados y de la miseria para la mayoría de la población hacía de los periodos festivos una ocasión inmejorable para dar la espalda a las preocupaciones y desgracias. La población se sumergía por unos días en un mundo ficticio de espectáculos, juegos, ocio, banquetes, aun a sabiendas de que, en no pocas ocasiones, era el propio pueblo el que sufragaba los gastos de estos festejos, bien de un modo indirecto a través de los impuestos, o directamente, ya fuera costeado por los lugareños o por los diferentes gremios artesanales.

Aunque el pueblo veía con satisfacción este tipo de fiestas, en estos días estaba vetada la jornada laboral y el humilde trabajador veía aún más mermados sus paupérrimos ingresos.

No obstante, a ojos de la Iglesia, el juego traía consigo más perjuicios que beneficios, uno de ellos será el desperdicio del tiempo. En este sentido, serán censuradas por el clero todas aquellas personas que ocupen parte de su jornada laboral en los mismos y, lo que será más peligroso, desatendiendo el oficio divino en días festivos. El existir legislación al respecto, penando con fuertes multas a los trabajadores que en estos días festivos no cumpliesen con sus obligaciones religiosas, hace suponer que los mismos no debían de acatar fielmente lo que dictaba la Iglesia. Esta era una medida de tantas que se tomaron, ante el miedo de las emergentes ideas reformistas que empezaban a llegar de Europa.

Es preciso señalar que la sociedad impuso los juegos que más convenían según la clase social a la que se pertenecía. El juego deportivo era distintivo de una parte muy pequeña pero importante de la sociedad, la nobleza. En este sentido, las justas, torneos, cañas, sortija, juegos de argolla y la esgrima serán, por lo general, exclusivos de los nobles. Es de reseñar que, aunque en el xvi estos juegos ya no tenían tan acentuado como en siglos anteriores la función de adiestramiento para la batalla, en el caso español, esta característica seguirá perviviendo aún.

El sector más numeroso de la sociedad estaba constituido por los llamados pecheros, aquellos sujetos obligados al pago de «pechos» o impuestos suponían aquel grupo social correspondiente a los plebeyos, es decir, la escasa clase media y la abundante clase baja, que representaban, en el I500, al 90 por ciento de toda la población. Bolos, dardos, saltos, carreras, luchas y otros juegos servían de recreación

Alcocer, Francisco de: Tratado del juego, Salamanca, I559, p. 302. 


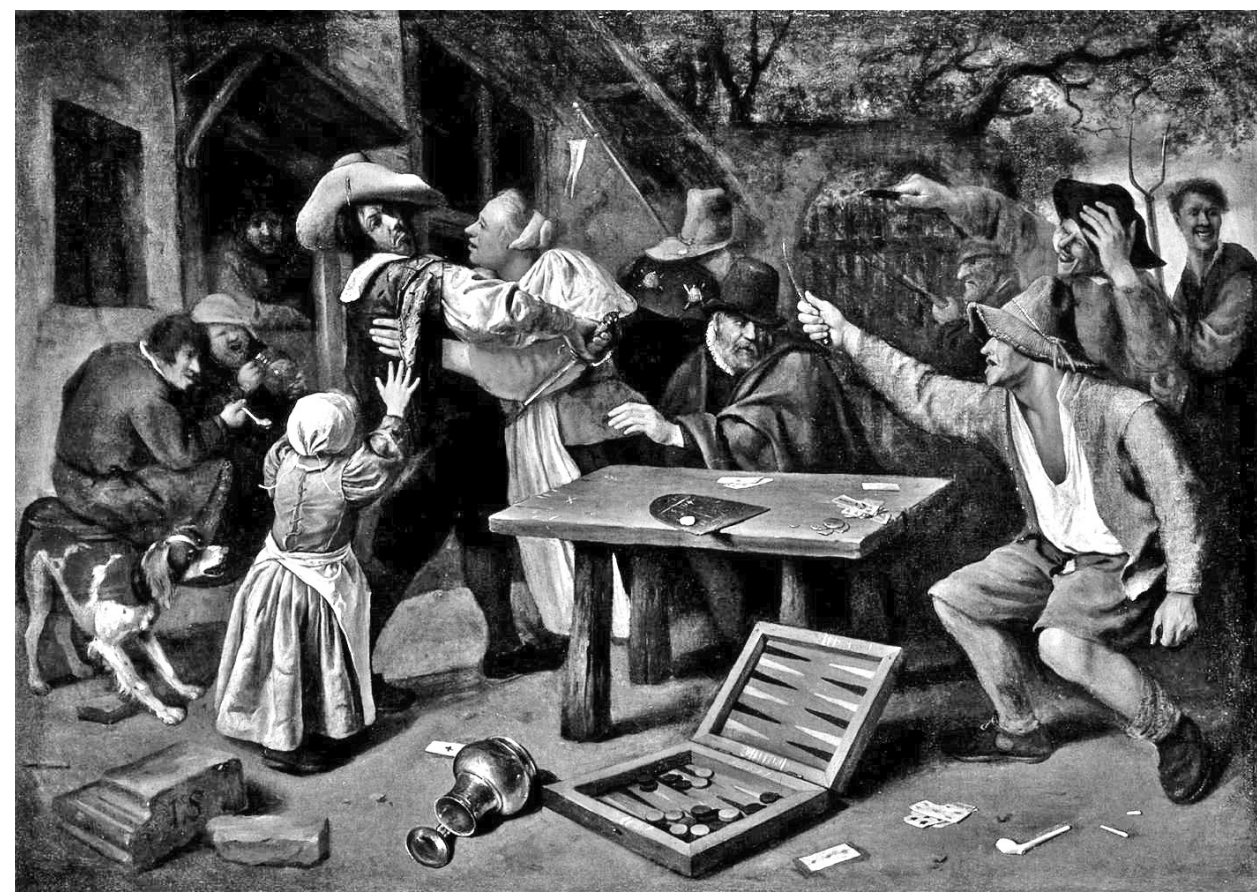

Imagen r. Discusión por un juego de cartas, Jan Steen.

para este colectivo. En contraste con los anteriores, los hidalgos y el clero quedaban eximidos de tributos.

A pesar de esto, algunas actividades eran comunes en todos los estamentos, como los juegos de pelota, la caza, la pesca, los bolos y, de un modo muy notorio, los tan temidos juegos de azar. Los juegos de azar más populares fueron los dados, los naipes y el juego de la tabla. A estos irán encaminadas las restricciones de la época, sobre todo cuando se pongan en el tapete cantidades excesivas de dinero, joyas u otros enseres de valor, como venía siendo habitual cuando los jugadores se quedaban sin efectivo. La abundante legislación que existió acerca del juego da a entender que preocupaba al gobierno todos los perjuicios que ocasionaba. Al mismo tiempo, denota que habitualmente la legislación no se cumplía y, como veremos más adelante, las penas impuestas las más de las veces tampoco se llevaban a cabo.

Para la Iglesia, la moderación será clave para resolver muchos asuntos, tanto en materia de pecado como de restitución. El clero no condenaba los juegos de azar o ventura, pero sí sus consecuencias, por tanto, dependiendo del uso que se le dé a este, así también será su consideración moral. Aunque en palabras de Alcocer, "el hombre nace para el trabajo, y el ave para bolar», si el juego se usa a su debido tiempo y lugar, no puede ser considerado como un acto ocioso, del mismo modo que tampoco lo es el dormir, pues sirve para restablecer las fuerzas. 
INSTRUYENDO SOBRE LA RECREACIÓN: ALCOCER Y LA MODERACIÓN EN EL XVI, CLAVE EN LA EDUCACIÓN PARA EL JUEGO IGNACIO LÓPEZ DE PRADO ORTIZ-ARCE

\section{El autor}

Desafortunadamente, es más lo que se desconoce de fray Francisco de Alcocer que lo que se puede afirmar con cierta verosimilitud. Según recoge Díaz, nacería en las primeras décadas del siglo xvi en Santiago de Compostela, después realizaría sus estudios en Salamanca donde coincidió con Francisco de Vitoria. De hecho, Díaz le señala como discípulo de este ${ }^{6}$. El mismo Alcocer, en el capítulo i6 del Tratado, afirma haber conocido a Vitoria y de sus palabras se revela cierto tono de afecto y admiración: «Esta cuestión yo vi tratar al padre Maestro fray Francisco de Vitoria varón de grande doctrina y muy conocido y estimado (y con mucha razón) en toda España»'. En la misma Universidad de Salamanca, según nos comenta el mismo Alcocer, estudió gramática.

Estudiando en aquella celebre y insigne vniversidad de Salamanca [...] Lo qual he querido yo mouer aqui por auerme criado desde que sali de la Grãmatica en ella y concurrir à ella la flor de los buenos y delicados entendimientos de nuestra España y de otras partes 8 .

Estuvo de fraile y posteriormente fue prior del convento de San Francisco el Grande en Salamanca, que a juicio de Villar y Macías fue una de las iglesias más imponentes de la ciudad ${ }^{9}$. Será en este convento donde, el 30 de noviembre de 1558 , obtendrá licencia para editar la primera de las obras del fraile de las que se tiene constancia, Tratado del Juego ${ }^{\mathrm{I}}$. No obstante, Alcocer no solo se dedicó a escribir sus propias obras. La notoriedad del fraile era tal que a menudo tenía potestad en la revisión y corrección de diferentes obras ${ }^{\mathrm{II}}$. Algunos de esos encargos fueron solicitados incluso por el mismo Felipe II, como ocurrió en la corrección de la Tercera parte de las Crónicas de la orden de San Francisco ${ }^{\mathrm{I2}}$.

6 Díaz Díaz, Gonzalo: Hombres y documentos de la Filosofía Española, Madrid, csic Press, I980, vol. I, p. I36.

Alcocer, F.: op. cit., p. 99.

Alcocer, F.: op. cit., p. 198.

9 Villar y Macias, M.: Historia de Salamanca, Salamanca, Graficesa, I974, vol. T, VI. p. 368.

1o Posteriormente escribirá otras dos obras de corte claramente moral, Reglas de rezar el Officio Dinino: y como se ha de dezir la Missa, según la Sancta yglesia Romana, como lo rezan y dizen los frayles menores, impreso en Salamanca en casa de Juan Cánova, 1566. Y Confessionario breve y provechoso para los penitentes. En el cual con toda brevedad y claridad se proponen los pecados ordinarios y comunes a todos, impreso en Salamanca en casa de Juan Cánova, I568.

II Sanz Hermida, Jacobo: La tercera parte de las chrónicas de fray Marcos de Lisboa (I570) y los franciscanos de Salamanca, 2002, p. 262. Fray Francisco de Alcocer examina el «manual corregido y añadido por el P. Alonso de Tarazona, vicario del choro del monasterio de sant Francisco».

${ }_{12}$ Ibidem, p. 265. Sanz Hermida nos comenta este episodio aludiendo al tono severo del monarca: «Dura censura a la que se referirá el rey Felipe II en la concesión del privilegio de Aragón otorgada al guardián de San Francisco. Juan de Reinoso: [...] podáys imprimir, o hazer imprimir, donde bien os pareciese de los dichos nuestros reinos y señorios de la corona de Aragón el dicho libro titulado. Tercera parte de las Chrónicas de la dicha orden de Sant Francisco. Con que en la dicha impressión se pongan en el principio del dicho libro las aprobaciones que fray Ioan de Vega, augustino, ha hecho dél, y se corrijan y enmienden las erratas que por fray Francisco de Alcocer se han hallado, en la que se ha hecho en Salamanca». 
INSTRUYENDO SOBRE LA RECREACIÓN: ALCOCER Y LA MODERACIÓN EN EL XVI, CLAVE EN LA EDUCACIÓN PARA EL JUEGO IGNACIO LÓPEZ DE PRADO ORTIZ-ARCE

En la obra Entre fray Luis y Quevedo, Blanco Sánchez señala que, aunque Alcocer no pertenecía a la Universidad, debió de estar en muy estrecha relación con ésta ${ }^{13}$. Sin embargo, Castro no solo deja intuir el título de doctor para el fraile, sino que alude a su función docente en la universidad ${ }^{\mathrm{I4}}$. Perteneciera o no al claustro universitario, lo cierto es que mantuvo una buena y estrecha relación con la institución, relación que fue muy longeva y perduró hasta el final de la vida del franciscano. Prueba de ello es que fue unos de los frailes comisionados por la Universidad de Salamanca para informar sobre la reforma del calendario juliano de $1583^{15}$. La comisión que iba a extender el informe, estaba compuesta, además, por otros varones ilustres, entre otros cabe destacar a fray Luis de León ${ }^{16}$. Es anecdótico destacar como, por orden del Papa, se premia la labor de Alcocer por los servicios prestados, sugiriendo se le regale un «hábito de fraile de buen paño» ${ }^{17}$.

Alcocer también sostuvo una buena amistad con el impresor Juan Cánova y, a la muerte de este, con su padre Alejandro Cánova, hasta que también falleció. Esto posibilitó que, desde comienzos de los sesenta hasta 1574, la empresa de los Cánova tuviera la concesión de prácticamente todas las obras franciscanas ${ }^{18}$.

No cabe duda de que el padre Alcocer fue admirado en su tiempo como un hombre de gran conocimiento:

En esta provincia murieron ansimesmo notables religiosos, entre los cuales murió el doctísimo P. Fr. Francisco de Alcocer cuyas letras y gran valor son conocidos por lo que dejo escrito, y en vida era su parecer entre los hombres más doctos de las escuelas de Salamanca y de toda España muy estimado y acepto. Está enterrado en el convento de San Francisco, de Salamanca ${ }^{19}$.

Según recoge Díaz, Alcocer fallece en $1580^{20}$. La «crónica de la provincia franciscana», como hemos visto, añade el lugar en el que fue enterrado el fraile.

\section{La obra}

En el año 1559 fray Francisco de Alcocer obtiene la licencia para su obra Tratado de juego, que se imprime anteriormente en Salamanca en casa de Andrea de

13 Blanco Sánchez, Antonio: Entre fray Luis y Quevedo: En busca de Francisco de la Torre, Salamanca, Atlas, 1982, p. 509.

${ }^{14}$ Castro, Manuel: «Impresos raros de la provincia franciscana de Santiago en el siglo XvI», Archivo ibero-americano, Madrid, n. ${ }^{\circ} 40$ (I58-159), (1980), p. I74. "Aunque los franciscanos no figuraban entre los doctores universitarios, no cabe duda de que el P. Alcocer enseñó en la universidad salamantina en la que gozó de universal prestigio».

${ }_{15}$ Según recoge el manuscrito 97 de la Biblioteca Universitaria de Salamanca, que lleva por título: Repertorio de los tiempos del año nuevamente fecho del año MDLXXVIII.

16 Otros eran Diego de Vera, Gabriel Gómez y, como secretario, Andrés de Guadalajara.

17 Blanco: op. cit., p. 5IO.

18 Hermida, J.: op. cit., pp. 26I-263.

19 Castro, Manuel: Crónica de la provincia franciscana de Santiago, I2I4-16I4: Por un franciscano anónimo del siglo XVII, Madrid, Marsiega, 1971, p. 260.

${ }_{20}$ Díaz Díaz: op. cit., p. 136. 
INSTRUYENDO SOBRE LA RECREACIÓN: ALCOCER Y LA MODERACIÓN EN EL XVI, CLAVE EN LA EDUCACIÓN PARA EL JUEGO IGNACIO LÓPEZ DE PRADO ORTIZ-ARCE

Portonarijs. Su obra perfectamente se podía haber llamado Tratado de lo lúdico, puesto que en el tratamiento de la misma da cabida a todo tipo de manifestaciones lúdicas. Así, el autor abordará los juegos de azar, como los naipes, las tablas y los dados, siempre muy relacionados con el mundo de las apuestas y suertes. Analizará los desafíos caballerescos, es decir, las justas, torneos, juegos de cañas, esgrima y el juego de la sortija. También investigará acerca de recreaciones más bien de carácter popular, como el juego de passa passa o los matachines, voltear, los toros, bailes y danzas, teatro y farsas, bufones, máscaras, el juego de pelota y otras cosas como el mismo autor dice «provechosas y dignas de saber».

Si le extirpamos a la obra la parte puramente legislativa, nos encontramos ante un tratado de las buenas maneras y la moderación. El autor enfatiza la idea de la restitución, en un intento de erradicar los males que se derivaban de las excesivas pérdidas en el juego. El hecho de que las diferentes leyes estuvieran a su vez interpretadas por juristas o doctores con diversas opiniones, hacía de la materia legislativa del juego un mar de confusiones. El mismo Alcocer reconoce que los doctores son muy diferentes unos de otros y que cada uno tiene su propia opinión, pero aun así ha intentado aunar las opiniones principales, resumiéndolas y exponiendo sus conclusiones ${ }^{21}$. De este modo, con la intención de instruir a los jugadores, Alcocer redacta todas aquellas situaciones susceptibles de duda en cuanto a la restitución. Si no hay incertidumbre a la hora de apoderarse de las ganancias en el juego, no surgirán, en opinión del autor, tantas desavenencias.

Una de las opiniones que el fraile enfatizaba en su obra es que no todos los juegos son condenables, incluso llega a la determinación de que ningún juego de por sí es condenable. El problema no radica tanto en la naturaleza del juego, sino en la utilización que se hace del mismo. Es el hombre el que transforma la naturaleza y los fines del juego en ilícitos y deshonestos. El hombre, con su nulo autocontrol, se deja llevar por el exceso, apostando en muchas ocasiones más de lo que posee. Los límites penados se excedían en muchas ocasiones y en cantidades exageradas, bien resultado de un par de juegos, o bien por la acumulación de cantidades más pequeñas en sucesivas partidas que, en no pocas ocasiones, se alargaban hasta la noche o incluso proseguían hasta el alba. Estos excesos no solo afectaban a los jugadores, sino que se extendían más allá, en sus mujeres, en los hijos o los bienes personales. En consecuencia, se producían abandonos del hogar, pérdidas de la manutención, de las herencias, penas de cárcel, enemistades, crímenes, etc. Pero, para el escritor, este exceso afecta también abandonando las tareas cotidianas, así como dejando de asistir a misa. Por lo tanto, el juego en sí no es pecado mortal, el pecado mortal vendría al no realizar las obligaciones, pero ojo, tanto religiosas, como laborales. Prueba de esto es otra de las obras compuestas por Alcocer, que gozó de una gran difusión, titulada: Confessionario brene y pronechoso para los penitentes ${ }^{22}$.

${ }_{21}$ Alcocer, F.: op. cit., p. 158 .

${ }_{22}$ Alcocer, F.: Confessionario breve y provechoso para los penitentes, Salamanca, Juan Cánova, 1568. 


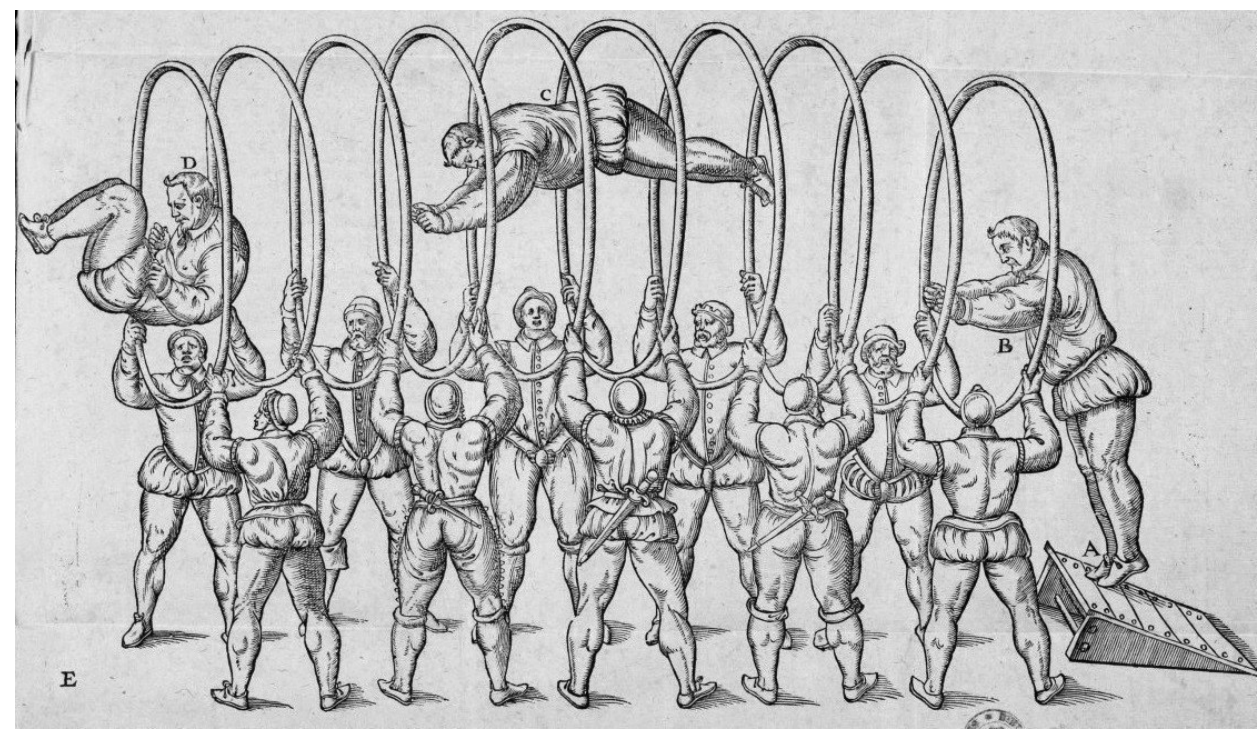

IMAgEN 2. Trois dialogues de l'Exercise de sauter et voltiger dans l'air, Archangelo Tuccaro, I599.

Pues bien, en dicha obra, en el capítulo XviI, «Del tercer mandamiento que es guardar los domingos y días de fiestas», no hace referencia alguna a manifestaciones lúdicas como la causa de no asistir a los oficios religiosos. Señala que cualquier tarea, sea la que fuere, que nos aparte de asistir a misa los domingos y fiestas será pecado mortal, excepto si se trata de poco tiempo, como de cinco minutos o un cuarto de hora, ya que entonces será solamente pecado venial.

En esta línea de impedir los perjuicios que ocasionan las prácticas lúdicas sin autocontrol, Alcocer repetirá en su obra, una y otra vez, la noción de la mesura. Esta idea, como ya vimos anteriormente, ya la sostenían también otros humanistas, como Luis Vives, sin ir más lejos. No obstante, Alcocer extiende aún más la idea del juego como algo beneficioso para la persona, pues para el fraile, aunque el juego se realizase por la mera recreación, también sería lícito.

Otra de las ideas que comparte Alcocer con Vives es la del juego adecuado a todas las edades y estados, pero de nuevo da muestras de un talante más abierto en cuanto a la práctica de las recreaciones por parte de los religiosos. Y no solamente le parece bien el juego en los prelados, sino también el hecho de que estos efectúen pequeñas apuestas, ya que si no en palabras del autor, «el jugar en seco es cosa muy fría» ${ }^{23}$. Ahora bien, guardarán el recato y la moderación necesarios a su condición, en este sentido, cuando disfruten del juego deberán procurar no ser vistos por la población laica. En esta línea, del buen ejemplo hacia los fieles, al confesor le atribuye labores de docente, puesto que algunos de los responsables

${ }_{23}$ Alcocer: op. cit., p. 31. «Porque si el fin y motiuo principal que mueue a los jugadores à jugar es la recreación y aliuio corporal, y porque el jugar en seco es cosa muy fria, se pone y juega alguna cosa moderada, licito es jugar la y dessear la ganar». 
INSTRUYENDO SOBRE LA RECREACIÓN: ALCOCER Y LA MODERACIÓN EN EL XVI, CLAVE EN LA EDUCACIÓN PARA EL JUEGO IGNACIO LÓPEZ DE PRADO ORTIZ-ARCE

de la ineficacia de las leyes, después del gobierno, serán los prelados. Esto se explica porque parte de su misión será informar a los creyentes acerca no solamente de la adecuada interpretación de las leyes, sino del modo correcto de participar en las diferentes recreaciones ${ }^{24}$.

Aunque la obra está dotada de cierto corte moral, no es menos cierto que una gran parte del tratado está destinada al aspecto legislativo de las diferentes prácticas lúdicas. Y uno de los mayores aciertos del fraile es haber sabido discernir en un mismo asunto el aspecto moral del civil. Es indudable que la vocación del autor no le ha cegado a la hora de abordar una cuestión y medirla por un doble rasero. Así, un determinado contrato, que es así como el fraile denomina a cualquier juego en el que se ha pactado una apuesta, puede ser lícito desde el punto de vista civil y, al mismo tiempo, pecado mortal a ojos de Dios, o en el mismo sentido, darse la situación contraria.

Llama también la atención en la obra la minuciosa descripción de diversas jugadas, tanto del juego de pelota, como del ajedrez o los naipes, que denota de un modo manifiesto que el fraile conocía el juego de una forma cercana. Es por eso que su obra está dotada de fuerza y peso suficiente, no solamente por estar hecha por una persona cultivada en las letras con una capacidad de análisis envidiable y unos razonamientos meticulosos, sino, también, por comprender el juego e incluso nos aventuraríamos a decir por practicarlo ${ }^{25}$.

\section{Juegos prohibidos}

Mas los gouernadores de las Republicas viendo que los hombres usaban mal de muchas cosas que ellas de suyo eran licitas, las prohibieron à sus subditos y dello hizieron estatutos y leyes humanas desseando tener las Republicas bien ordenadas y disciplinadas y desterrados dellas los vicios y viciosos. Y como vna delas cosas acarreadoras de vicios y rayz dellos, sea el juego excesiuo y demasiado, prohibieron ciertas maneras de juegos, y que no se pudiese jugar mas de hasta cierta cantidad ${ }^{26}$.

Con estas palabras, Alcocer expresa la necesidad de las leyes en torno al juego, el cual en sí mismo no contiene mal, sino que es el hombre el que no lo usa de un modo adecuado. En general, la abundante legislación que surgió en el xvi con la intención de controlar los excesos en el juego se dirigió principalmente a los llamados juegos de azar y ventura, es decir, los dados, los naipes y el juego de la tabla. Es interesante el caso del juego de pelota, pues a lo largo de este siglo pasó por diferentes periodos, desde la prohibición más absoluta hasta la recomendación de

${ }^{24}$ La sociedad española del xvi es en su mayoría analfabeta. En este sentido, será muy importante el papel del confesor, así como las representaciones visuales a la hora de entender el mensaje de la Iglesia.

${ }_{25}$ Alcocer: op. cit., pp. II4-I2I. En este sentido, es muy llamativa la descripción que ofrece Alcocer de diferentes jugadas en juegos tan diversos como el ajedrez, los naipes, la pelota o las tablas.

${ }_{26}$ Ibídem, p. 36. 
INSTRUYENDO SOBRE LA RECREACIÓN: ALCOCER Y LA MODERACIÓN EN EL XVI, CLAVE EN LA EDUCACIÓN PARA EL JUEGO IGNACIO LÓPEZ DE PRADO ORTIZ-ARCE

que se fomentase su práctica ${ }^{27}$, pasando también por un término medio, en el cual se podía jugar, pero solo apostando cierta cantidad.

A través de fueros, ordenanzas y normativas concejiles, se intentaron detener los excesos cometidos en el juego. A pesar de esto los juegos de azar y las apuestas estaban tan arraigados en la población que incluso con las diferentes condenas no se consiguió erradicar esta costumbre. Ni siquiera la Iglesia bajo pena de excomunión o pecado mortal consiguió extinguir este vicio. Es preciso señalar que, en la sociedad del xvi, cualquier situación podía ser objeto de apuesta, un simple salto, el juego de pelota, si el hijo del rey nacerá varón o hembra, si será año de sequía, si zozobrará tal nave, etc.

Los perjuicios de los juegos de azar son tan notables que corrientemente las partidas terminaban degenerando en riñas o peleas con graves daños físicos y, en ocasiones, con la muerte, por no contar con la destrucción de los bienes y el desorden social que generaban.

Existen varias razones por las que estos juegos fueron una plaga difícil de erradicar en la sociedad del xvi. En primer lugar, y a diferencia de los juegos de origen caballeresco en los que, por lo general, las prácticas se desarrollaban en días festivos, estos podían llevarse a cabo cualquier día y época del año realizándose, por tanto, de un modo cotidiano.

Otra de las razones fue por su accesibilidad. A pesar de la existencia de casas de juego o tablajes dedicados exclusivamente a este tipo de prácticas, el vicio no se quedaba ahí, se jugaba en la calle, en las tabernas, en los burdeles, en los palacios, en la guerra o hasta en la mismísima iglesia y, como hemos mencionado, por todas las clases sociales.

Los intereses creados formaban parte también de los obstáculos que había que vencer en la lucha contra el juego. Esto se explica porque el entorno en el que se desarrollaban estas recreaciones comprendía no solamente el de los propios jugadores, sino que existía todo un escenario de diferentes personajes, intentando obtener alguna clase de beneficio. Desde los espectadores o los ayudantes de los jugadores que perseguían conseguir algo de barato ${ }^{28}$, a los organizadores que prestaban sus casas o los comerciantes de material lúdico que se lucraban alquilando dichos enseres, así como toda clase de pícaros esperando la oportunidad de obtener algún provecho. En este sentido, la Corona formaba parte también de este grupo consolidado de los que se lucraban con los juegos de azar, pues obtenía un ingreso sustancial en concepto de impuestos a las casas de juego o «tablajerías», así como por la venta de dados, tablas u otro material. Por último, es necesario resaltar el negocio de la usura. El perfil de los jugadores solía corresponder con personas de pocos recursos, estos se veían en la necesidad de recurrir a prestamistas

27 Pino Abad, M.: El delito de juegos probibidos: análisis histórico-jurídico, Madrid, Dykinson, 20II, p. 77. Se solicita al soberano que ya que el juego de la pelota no está prohibido, sería positivo que se fomentase su práctica, aunque habría que tener cuidado que los jugadores reciban créditos por la costumbre de apostar más de lo que se tiene.

${ }_{28} \quad$ El barato era cierta cantidad de dinero que daba voluntariamente a algunos de los presentes en el garito quien ganaba en el juego, por facilitarle la tarea, dándole casa, velas o naipes para jugar. 
INSTRUYENDO SOBRE LA RECREACIÓN: ALCOCER Y LA MODERACIÓN EN EL XVI, CLAVE EN LA EDUCACIÓN PARA EL JUEGO IGNACIO LÓPEZ DE PRADO ORTIZ-ARCE

para solventar las deudas, o bien para seguir jugando. La cuestión era de tal magnitud que el mismo Alcocer relata cómo lo que se jugaba en efectivo era una pequeña parte respecto de lo que se jugaba a crédito ${ }^{29}$.

Además de todas estas complicaciones, nos encontramos con un contexto generalizado en el cual la aplicación de las leyes, en la mayoría de las ocasiones, causó poco o nulo efecto en el intento de abolir los juegos de azar. Por ejemplo, la realidad nos enseña que si una ley tan represiva, como la que en su día dictó la reina doña Juana no surgió el efecto deseado es porque sin duda la aplicación de la misma fue bastante laxa e incluso, en ocasiones, no se llevó a la práctica ${ }^{30}$. ¿Entonces, qué se podía esperar de otras leyes que en su momento se implantaron no tan severas? Un buen ejemplo de esta laxitud a la que nos venimos refiriendo nos lo encontramos en la determinación de las Cortes de Madrid de i528. Como consecuencia de las grandes cantidades que se apostaban en el juego de pelota, se dicta una ordenanza en la que se prohíbe jugar tanto a crédito como a fiado a cualquier juego de los permitidos, como el mencionado. Pero además, y aquí viene la paradoja, se ordena que, en caso de incumplimiento, no se condene a los jugadores a pena alguna, ni a devolver las cantidades prestadas ${ }^{31}$. Aunque esta ordenanza se creó con el propósito de evitar los negocios de usura, advirtiendo a los jugadores que no tenían obligación de devolver lo que hubiesen recibido, la realidad era que las leyes trajeron aparejadas una serie de salvedades que ayudaban poco o nada a controlar los excesos en el juego. Estas excepciones fueron de lo más variadas: si se juraba haber jugado a otro juego en vez de a uno de los prohibidos; si se jugaba solamente cantidad de dos reales, o bien cosas de comer; si se admitía desconocimiento e ignorancia en la prohibición de la ley; si habían pasado más de dos meses desde que se cometió la falta, etc. Todas estas excepcionalidades las acusa Alcocer, manifestando que mientras que las penas no obliguen a devolver las cantidades apostadas no se conseguirá erradicar «los juegos demasiados y viciosos: porque jugaran como hasta allí y buscaran mil maneras de defraudar las y engañar a los juezes» ${ }^{32}$.

Otra de las razones que explicarían la escasa efectividad de las ordenanzas sería el uso de la costumbre, la cual podía derogar tanto leyes civiles como canónicas. La costumbre no fue otra cosa que claudicar ante lo inevitable ${ }^{33}$. El uso y

Alcocer: op. cit., p. 166.

30 Ibídem, pp. 40-4I. Ley de la Reina Doña Juana, Burgos, I5I5. La pena será la misma para los jugadores como para todos aquellos que ayudan al desarrollo de los juegos. La pena será de dos años de destierro, más la sustracción de las ganancias, además deberán pagar veinte mil maravedís, y las casas donde se haya jugado o las tiendas donde se ha comprado el material lúdico serán confiscadas.

${ }^{31} \quad$ Ibidem, p. 42. "... mandamos que de aqui adelante ninguna persona de qualquier estado ò calidad que sea, pueda jugar ni juegue, à credito ni à fiado aunque sea juego de pelota ni otro de los tolerados y permitidos en estos Reynos. E si jugaren los dichos juegos à crédito ò fiado, mandamos a las nuestras justicias que no condenen ni executen en las tales personas, ni en sus bienes, ni en los de sus fiadores lo que assi deuieren de los dichos juegos à credito ò fiado, que por la presente damos por ningunas qualesquier obligaciones, escrituras, ò promessas, que las tales personas à cerca delllo hizierren».

32 Alcocer: op. cit., p. 197.

33 Ibidem, p. 46. 


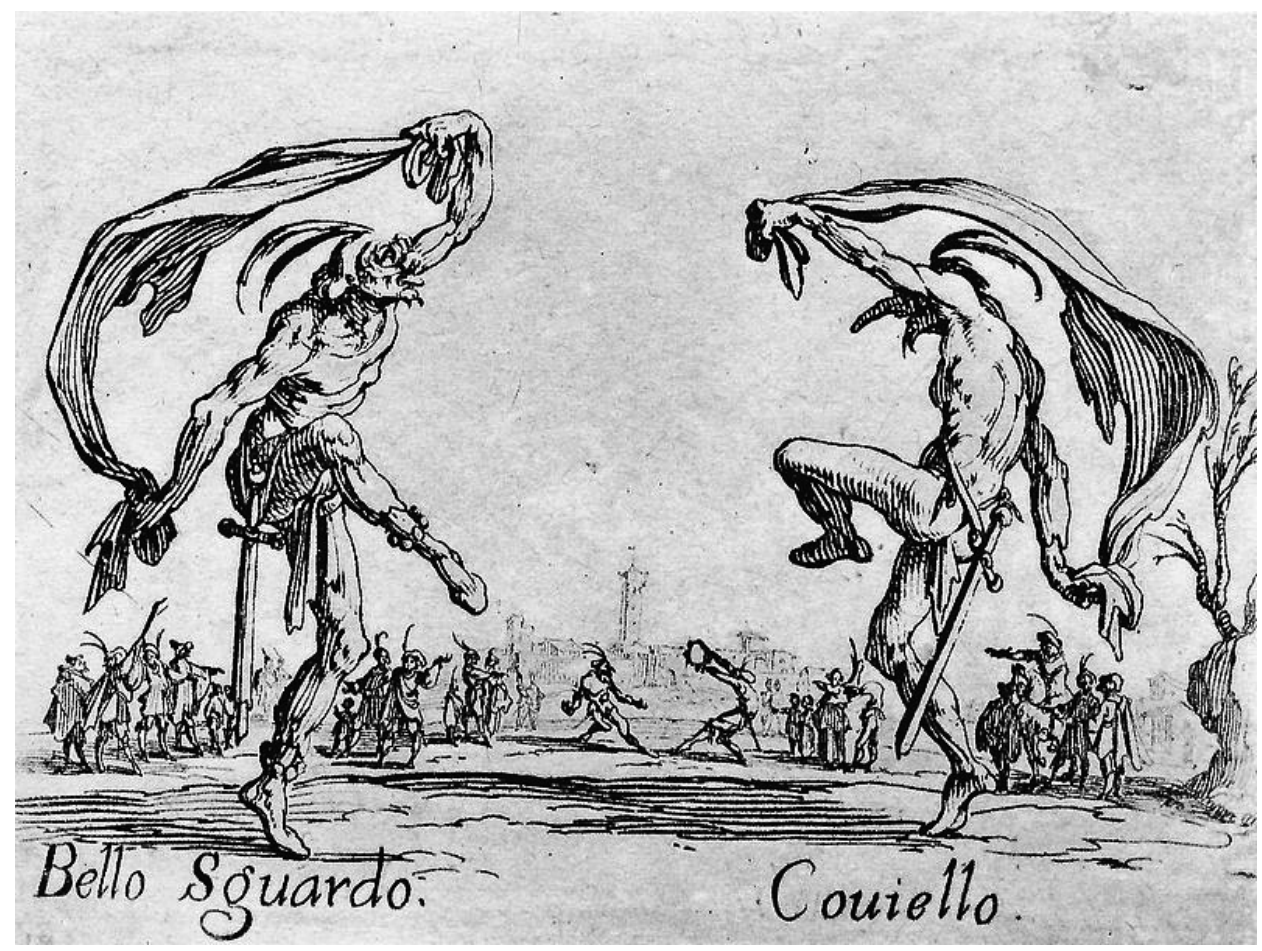

Imagen 3. Balli di Sfessania Bello Sguardo and Coviello, Jacques Callot, I620.

abuso de una determinada práctica prohibida, a la larga, producía el agotamiento de la ley, y con este agotamiento surgía la implantación de una nueva ley, suprimiendo a la anterior, y es entonces cuando en palabras de Alcocer se puede decir que «la costumbre ha derogado la ley».

En cuanto a las penas que emanaban de las diferentes leyes, iban desde los azotes en público, al pago de una cierta cantidad, el destierro, la prisión o incluso las galeras. Aunque la aplicación de estos castigos dependerá de la clase social a la que se pertenezca, a tenor de lo referenciado por Alcocer, la justicia denotaba un trato de favor hacia los estamentos más privilegiados.

Pero esta diligencia y pesquisa no sea contra los flacos y plebeyos y gente ciudadana y llana solamente, sino contra todo genero de gente baxa, mediana y del mas alto estado que hubiere. Porque si se dexan las publicas tablajerias en las casas de los grandes señores y caballeros y no se haze pesquisa dellas ni castigan, y proceden contra un hombre ciudadano que jugo por ventura una ò otra vez, con todo el rigor de la ley, [...] esto no es justo ni buena gobernacion: y es hazer las leyes semejantes a las telas de las arañas que caçan las moscas pequeñas y las grandes no las puede prender ${ }^{34}$.

$34 \quad$ Ibidem, p. 197. 
INSTRUYENDO SOBRE LA RECREACIÓN: ALCOCER Y LA MODERACIÓN EN EL XVI, CLAVE EN LA EDUCACIÓN PARA EL JUEGO

\section{Algunas recreaciones populares}

Estas tres prácticas que se presentan a continuación, el voltear, el juego de passa passa y los matachines, son tratados en un mismo capítulo de la obra, puesto que para el autor «este tipo de cosas se representan en farsas y fiestas temporales»35. Para Varey, estas actuaciones, a veces conjuntas, de acróbatas, jugadores de manos y títeres, se clasificaban como funciones no dramáticas, razón por la que solían escapar a las prohibiciones de la cuaresma, logrando gran popularidad al empezar y terminar la temporada teatral ${ }^{36}$. Tales circunstancias hacen sospechar que estas actividades pudieron organizarse como verdaderas compañías, tal vez yendo de pueblo en pueblo, como afirma Montoto que hacían los jugadores de passa passa $a^{37}$.

\section{I. Del voltear}

«Volantines, funambulistas, petauristas», todos estos nombres servían para definir a las personas que se dedicaban a estas actividades «circenses». Para Alcocer:

El voltear assi sobre una maroma como sobre espadas cruzadas y en otras maneras que se usan, es otra manera de regocijo y juego que se inuento y usa para recreacion y aliuio de los trabajos corporales ${ }^{38}$.

Ciertamente da la sensación de ser un ejercicio no exento de peligrosidad. Dar una vuelta por encima de unas espadas cruzadas, a priori, debe entrañar su dosis de riesgo, sin embargo, para el fraile es un ejercicio lícito por hacerse «sin peligro de la vida o de lesión». Aunque, más adelante, señala que si hubiese peligro de «lesión corporal o de la vida» sería pecado mortal y no solamente para los saltadores, también de organizadores o de personas que demandan el ejercicio sabiendo que existe ese peligro. Ahora bien, los espectadores que simplemente se recrean «dela sutileza y ligereza con que los bolteadores lo hazen» no cometerían ningún tipo de pecado, siempre que no disfruten «del daño que les succede ni del peligro à que se ponen" ${ }^{39}$. Dentro de esta actividad se distinguían: el petaurifta o volatin, se llamaba así a los que solían dar vueltas en el aire y en el suelo o pasando a través de unos aros de mimbre. Algunas de las destrezas se siguen practicando hoy en día.

Ibídem, p. 305. «Capitulo. IV. Del boltear y juego de passa passa».

36 VAREY, J. E.: «Representaciones de títeres en teatros públicos y palaciegos: I2II-I760», Revista de Filología Española, Madrid, vol. 28 (1954), pp. 178, 182, 209.

37 Montoto y Rautenstrauch, L.: Personajes, personas y personillas que corren por las tierras de ambas castillas, Sevilla, librería de San José Francos, I9II, p. I6I.

${ }_{38}$ Alcocer: op. cit., p. 305.

39. Ibidem, p. 306. 
INSTRUYENDO SOBRE LA RECREACIÓN: ALCOCER Y LA MODERACIÓN EN EL XVI, CLAVE EN LA EDUCACIÓN PARA EL JUEGO IGNACIO LÓPEZ DE PRADO ORTIZ-ARCE

... el salto de la trucha, el ovillo, el molino. Este se haze poniendo la cabeça enel suelo: y dando bueltas con el cuerpo a la redonda; a una y otra mano ${ }^{40}$.

... los que llaman bolatines, gente prodigiosa en materia de saltos, por hazerlos de mil maneras, al parecer con no poco peligro; assí tienen algunos nombres de mortales ${ }^{4}$.

El «funambulo» hacía todo tipo de destrezas, incluso volteos, solo que encima de una maroma. Según nos describe Covarrubias «tambien con zancos, con bolas, con cazoletas en los pies: y metido el hombre en un costal, y atado, va a tiento passando por la maroma, que tienen los hombres abobados» ${ }^{42}$. Este tipo de actividad ya existía en la antigüedad, siendo curioso el dato que aporta Suárez cuando comenta que en Roma también danzaron los elefantes sobre la maroma «siguiendo el compás de un palo» ${ }^{43}$.

\subsection{Juego de passa passa}

Al ser conocido este juego con varios nombres, hace pensar que debía ser relativamente común. Alcocer lo define como el juego de passa passa, «Ay otras invenciones y juegos que llaman de passa, que algunos de ligeras y subtiles manos usan...» ${ }^{44}$. Este era un juego de manos similar, por no decir igual, al actual juego del trile. Se solía jugar con unos cubiletes y pelotillas, a veces sustituidas por avellanas, bolas de cera, agallas, etc. El diccionario de autoridades utiliza el término de titiriteros para designar a estos jugadores ${ }^{45}$. Sin embargo, Covarrubias lo define como «maestre coral», y la explicación que nos ofrece para este nombre es que «los charlatanes y embusteros que traen estos juegos, se desnudan de capa y sayo y quedan en unas jaquetas ó almillas coloradas, que parecen troncos de coral»46. El mismo Covarrubias nos comenta cómo este juego consistía en meter dentro de unos cubiletes unas pelotillas, después se movían dichos cubiletes dando unos golpes con un palillo, al tiempo repetían las palabras de «passa passa» y, como por arte de magia, las pelotillas iban pasando de un cubilete a otro en sucesivas jugadas ${ }^{47}$. Se conocía a estos jugadores de manos también con el nombre de «sacularios», pues llevaban consigo una burjaca, dentro de la cual había juguetes que sacaban y metían dentro, para despertar el interés del público, y vender dichos

40 Covarrubias Orozco, Sebastián: Tesoro de la lengua española, Madrid, Luis Sánchez, I6II, p. I45.

4I Suárez Figueroa, C.: Plaza universal de todas ciencias y artes, Madrid, Luis Sánchez, I6I5, p. 325 .

Covarrubias: op. cit., p. 145 .

SUÁREZ: op. cit., p. 325v.

Alcocer: op. cit., p. 306.

RAE: Diccionario de la lengua castellana, Madrid, Francisco del Hierro, 1726-1739, p. 326.

Covarrubias: op. cit., p. 237. Véase, también, «masicorales» p. 580, y «acetabularij», p. 493.

Ibidem, pp. 493-494. 
INSTRUYENDO SOBRE LA RECREACIÓN: ALCOCER Y LA MODERACIÓN EN EL XVI, CLAVE EN LA EDUCACIÓN PARA EL JUEGO IGNACIO LÓPEZ DE PRADO ORTIZ-ARCE

juguetes. Así, por alusión, se llamaba sacularios a los que mostraban los juguetes que contenía el saco.

... llama el derecho sacularios a los que muestran las mercadurias a la boca del saco, o del costal, y lo que parece es bueno, y lo que se encubre malo, con que engañan al que lo compra si lo lleua con el mismo saco, o cesto, o vaso, que todo viene a ser un mismo engaño, y genero de hurto, y ladronicio ${ }^{48}$.

Uno de estos engaños, para Covarrubias, era el de la cola de una ardilla con dos cascabeles, que hacían que pareciese viva, asomándola por la «bolsa de las trampas» ${ }^{49}$, y metiéndola dentro tras darla unos golpes, para luego sacarla nuevamente y pasarla por la cabeza y cuello.

\subsection{Los matachines}

Ay otros juegos [...] que llaman Matachines: los quales con otras invenciones semejantes y niñerias de danças y juguetes que extrangeros traen para sacar dineros de la gente vulgar y popular que se mueve à cada niñeria semejante que sale (y aun si dixesse que también se mueven y van à ver semejantes niñerias gente mas que vulgar, no erraria $)^{\varsigma \circ}$.

De las palabras de Alcocer se deduce que este tipo de diversión debía de congregar buen número de personas y ser del gusto de la población, razón por la que estas representaciones obtendrían unos ingresos relevantes. Es esta la causa por la que el fraile no oculta su desagrado, «avian los buenos juezes y governadores de desterrar de las ciudades y provincias donde residen: porque hagan dellas mucha suma de maravedis» ${ }^{\lessgtr}$. Aun así, según el criterio de justicia del fraile, no pueden ser tachados de cometer pecado mortal ni los que traen estos espectáculos ni los espectadores. Ni siquiera aunque se muestren de manera gratuita o por un precio moderado.

Según nos informa Ramos, el nombre de matachín servía para denominar tanto a un personaje como un tipo de baile ${ }^{\text {s2 }}$. El personaje del Matachín proviene de Italia, a principios del xvi. Este se vestía de un modo ridículo portando una espada de madera, solía efectuar algún tipo de baile que provocaba más risa que admiración. A todo este atuendo solía añadirse el de una careta con una gran nariz. Respecto al baile que realizaba con frecuencia en las fiestas de carnaval, se llevaba a cabo al término de las mojigangas, en las cuales hacía su aparición el personaje de Matachín. No obstante, según Ramos, todas las apariciones de los matachines no implicaban que estos bailaran la danza que lleva su nombres3.

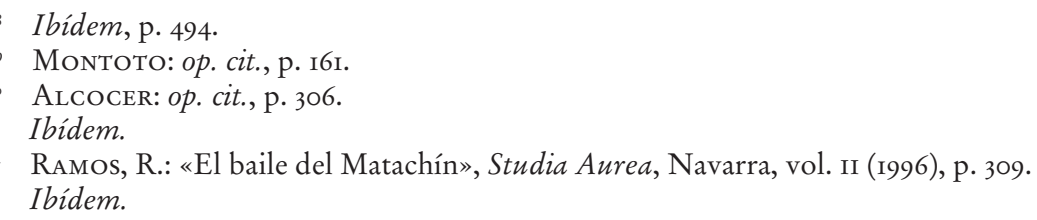


INSTRUYENDO SOBRE LA RECREACIÓN: ALCOCER Y LA MODERACIÓN EN EL XVI, CLAVE EN LA EDUCACIÓN PARA EL JUEGO IGNACIO LÓPEZ DE PRADO ORTIZ-ARCE

Para Covarrubias el nombre de matachín deriva del verbo matar ${ }^{54}$. Así mismo, nos comenta cómo la danza del mismo nombre era muy semejante a la que bailaban los de Tracia. Protegidos con celadas, escudos y armados con alfanjes, dejando al descubierto los brazos y las piernas, al son de las flautas danzaban, saltaban y se golpeaban fuertemente los unos con los otros. El público allí congregado creía que efectivamente tenían la pretensión de herirse y matarse. De este modo, algunos actores se desplomaban en el suelo y los vencedores les despojaban de sus armas al tiempo que gritaban «ivictoria!», yéndose triunfantes al ritmo de las flautas. Debido a esta aparente matanza, se denominaba La Danza de los matachines. Ahora bien, una cosa es la descripción «romántica» que nos ofrece Covarrubias de la danza que llevaban a cabo los tracios y otra diferente la que con el paso del tiempo se debió de realizar en el xvi, puesto que las descripciones que se nos ofrecen, tanto del atuendo como de la vestimenta, no son tan «elegantes». Así, el diccionario de autoridades define Matachín como:

Hombre disfrazado ridiculamente con carátula, y vestido ajustado al cuerpo desde la cabeza a los pies, hecha de varios colores, y alternadas las piezas de que se compone: como un quarto amarillo y otro colorado. Fórmase destas figuras una danza entre quatro, seis u ocho, que llaman los Matachines, y al son de un tañído alegre hacen diferentes muecas, y se dán golpes con espadas de palo y vejigas de vaca llenas de aire"s.

A pesar de la disconformidad con algunas de estas prácticas, Alcocer no duda en que todas las ganancias obtenidas, tanto si se han obtenido por realizarlas, como por formar parte de las mismas, se adquieren de un modo justo y no hay obligación de devolverlas. Y esto sería así incluso en el caso de voltear con peligro de la vida, porque no es suficiente que en el acto en el que se ha adquirido una ganancia hubiera pecado mortal para que dicho bien no se adquiera justamente.

\section{Consideraciones finales}

Haciendo un análisis porcentual de la obra, nos encontramos con una realidad, casi el ochenta por ciento de la misma se ocupa del aspecto legal de la retribución obtenida a través del juego y otras problemáticas relacionadas como los fraudes, suertes, apuestas, etc. Solo un dieciocho por ciento de la misma está exclusivamente dedicada al pecado y los diferentes mandamientos. Por consiguiente, es fácil entender que la preocupación principal del autor estaba en las pérdidas ocasionadas por el juego y los conflictos que generaban. Esta preocupación por el juego no fue exclusiva del fraile, pues ya la expusieron otros autores

54 Covarrubias: op. cit., p. 542.

"RAE: op. cit., p. 5IO. Véase también «Pata galana: hombre disfrazado y vestído ridículamente, como de Matachín, que suele ir en las procesiones del Santifsimo apartando la gente u otros estorbos», p. 160. 
INSTRUYENDO SOBRE LA RECREACIÓN: ALCOCER Y LA MODERACIÓN EN EL XVI, CLAVE EN LA EDUCACIÓN PARA EL JUEGO IGNACIO LÓPEZ DE PRADO ORTIZ-ARCE

de la época ${ }^{56}$. Las argumentaciones a favor y en contra del juego se exponen desde una doble perspectiva legislativa, la de las leyes canónicas y las del reino o civiles, demostrando que un mismo asunto puede ser pecado mortal y al mismo tiempo no estar penado civilmente, siendo, por tanto, lícito adquirir las ganancias. Este doble enfoque dota a la obra de una gran neutralidad y sensatez a la hora de exponer las conclusiones. No obstante, es importante señalar que en el aspecto legislativo del juego existió una dualidad de intenciones. De este modo, por un lado, se intentaba censurar sus prácticas por parte de los sectores morales, económicos o sociales y, del otro, se reconocía el juego como un derecho humano. Así se entiende que los intentos de supresión demostraran siempre su ineficacia, porque en el fondo no existía una clara intención de erradicar el juego en su totalidad. Respecto de los tan temidos «juegos prohibidos», hay que resaltar que, tanto para el derecho natural como para el divino, todos los juegos son lícitos y permitidos sin hacer distinción entre ellos. El motivo por el que la Iglesia y el Estado los condenan es debido a la osadía de apostar todos los bienes al azar de cómo saldrá determinada jugada. De cualquier modo, si se juega alguna cosa moderada, lícito es jugarla y desearla ganar. Y llegado el caso de apostar cantidades más grandes, dependerá de «la calidad de las personas». Si estas disponen de suficiente dinero para gastarlo, sin perjudicar a terceros y poner en riesgo las propiedades, la codicia no pasará de pecado venial. Del mismo modo, si el juego se usa «templadamente y en lugares y tiempos convenientes» no solo es «obra virtuosa», sino necesaria cuando se realiza con el fin de renovar las fuerzas del trabajo diario. Incluso aunque el juego no esté al servicio del trabajo y se realice por el mero deleite, no podrá considerarse como pecado mortal, tan solo llegaría a la consideración de pecado venial.

Alcocer, citando a Aristóteles, resalta la necesidad del juego, pues así como es vicio jugar demasiado, también lo es «nunca jugar y faltar en el juego» ${ }^{57}$. De esta manera, para el fraile el juego es necesario para todo género y estado de perso$n a s^{58}$. Es más, advierte el fraile que no solo en la religión cristiana, sino también en otras «religiones de grande exemplo y dotrina», usan la recreación en sus fiestas principales. En este sentido, todas aquellas personas que se dedican al trabajo «espiritual», como los religiosos, estudiantes, juristas, etc., al ser estos trabajos «mayores» que los trabajos corporales de los labradores u oficiales, necesitarán en mayor medida de las recreaciones. Por otro lado, la excesiva dedicación al juego puede incurrir en pecado mortal si se desatienden ${ }^{59}$ las obligaciones como

s6 Covarrubias: op. cit., pp. 493-494. En la definición de juego: «El es un vicio que trae tras si otros ciento: cada dia se reprehende en los pulpitos: $\mathrm{y}$ tratados ay escritos dello, y no quiero salir de mi proposito, solo advierto que en ninguna cofa tanto descubre el hombre su talento como en el juego [...]».

57 Alcocer: op. cit., p. 3.

${ }_{58}$ Alcocer: op. cit., p. 4. «... en hombres y mugeres: en niños, moços y viejos: en solteros y casados: en oficiales, labradores y cavalleros: en seglares y clerigos: en religiosos y religiosas y Obispos, con tal que como se declara en el discurso deste tratado, cada uno use de la recreacion y juego que conviene y es decente a su estado».

59 AlCocer: op. cit., p. I9. Para el fraile es triste observar cómo las hormigas aprovechan mejor el tiempo que las personas, pues estas se preocupan por el invierno abasteciéndose en el verano. 
INSTRUYENDO SOBRE LA RECREACIÓN: ALCOCER Y LA MODERACIÓN EN EL XVI, CLAVE EN LA EDUCACIÓN PARA EL JUEGO

IGNACIO LÓPEZ DE PRADO ORTIZ-ARCE

la familia, el trabajo o la misa. Pero es preciso señalar que el pecado no lo causa el juego como tal, sino cualquier actividad que cause este abandono.

Ahora bien, en una sociedad mayoritariamente analfabeta, el mensaje del ejemplo que hay que dar ante el creador y las consecuencias que acarrea no llevar una vida ejemplar han de enseñarse por diferentes cauces. Así, las farsas serán aceptadas mientras no se escenifiquen aspectos irreverentes o provocativos de lujuria. Por su parte, el confesor será el transcriptor de las leyes, formando parte de su misión instruir a los creyentes acerca no solamente de la adecuada interpretación de las leyes, sino de la manera correcta de participar en las prácticas lúdicas. En esta línea aclaratoria, la obra, con un claro estilo pedagógico, ofrece numerosos ejemplos de la vida cotidiana, jugadores profesionales, prostitutas, padres de familia, amas de casa, estudiantes, asesinos, bufones y un largo etcétera.

Nos encontramos, por tanto, ante un tratado eminentemente jurídico con notables tintes humanistas. No solo por la consideración de la necesidad del juego para el ser humano, las constantes referencias a lo largo de toda la obra a los autores clásicos, sino por la idea de la moderación como canalizadora de la práctica lúdica.

Por esta opinión hace lo que se lee en las Colaciones de los padres, del glorioso Apóstol y Evangelista San Juan, del qual como se escandalizasse uno viendo le jugar con sus discipulos, mando le que flechasse muchas veces un arco con una saeta, y preguntole si podria durar en aquello por mucho tiempo. Y el dixole que se quebraria el arco si lo hazia muchas veces, y respondiole el glorioso Apostol, que tambien se quebrantaria el ánimo del hombre sino usava de alguna recreación ${ }^{60}$.

${ }^{60}$ Alcocer: op. cit., p. 4. 